\title{
USAGE OF IT IN THE PROCESS OF TOPOGRAPHIC MAP CREATION IN MGI
}

\author{
Viktor Marković, \\ Saša Bakrač \\ Nina Dimitrijević, \\ Radoje Banković, \\ Siniša Drobnjak
}

Military Geographica Institut, Belgrade, Serbia

Correspondence:

Saša Bakrač

e-mail:

sbakrac2017@gmail.com

\begin{abstract}
:
Usage of GIS in MGI is a standard in the production process of the geographic and cartographic information considering geospace and maps. This paper main scope is a review of the central geospatial database as a base for a technological process which main purpose is production of topographic maps. In the central geodatabase environment, MGI has developed its own technological production line, which is based on family of Microsoft Windows operating systems (standard desktop license and the server license). In some production phases, it is necessary to use additional specialized software to achieve rounded production process which is capable of dealing with such a complex task.
\end{abstract}

Keywords:

Military geographical institute (MGI), GIS, map, geodatabase, geospace.

\section{THE INITIAL CONSIDERATION ABOUT MGI INFORMATION SYSTEM}

In the information system of MGI (IS MGI), the client-server architecture is implemented, where the network is service oriented. This concept is beneficial in multiple ways, and, as for the main advantage of such approach, we can point at: centralized management of services and clients and network administration, centralized security policy, easier backup of the entire system as well as backup on the local workstations [1]. Out of the many network services which exist in IS MGI, two services have the greatest impact on the process of topographic map production. These services are Microsoft Active Directory and Image Services.

The Active Directory has become a necessary service for the contemporary business. It serves as a central spot for the information storage about the users identity, workstations, services, authentication of users and workstations and provides the mechanisms, with which, users and workstations are able to gain access to the network resources (printers, plotters, file sharing, databases etc.). 
The main role of the Active Directory is to provide the complete identity and access infrastructure, which consists of tools and technologies necessary for the integration of persons, processes and technologies within a single organization. The basic functions of such directory are:

Authentication - every single user, workstation or some other predefined entity in the network, has to confirm its identity to the Active Directory before it is allowed to function as a part of the Active Directory domain;

Controlled access - The Active Directory keeps all of the data (files and folders, the Active Directory objects) and the resources (workstations, printers, services etc.) which are placed inside the domain, ensuring that the access is allowed only to those identities which are meant to gain access to them;

Monitoring - The Active Directory has the tools and mechanisms which enables surveying, corrections and reporting;

Increased security - By the usage of the Active Directory, the security of the both network and the data is significantly increased, because the data considering identities and their passwords are kept inside encrypted database. All of the common users have limited access to both workstations and the network. For example, they are unable to install any additional software, which is the main source of the malicious software.

Simplified deployment - Installation and reinstallation of the client operating systems and applications, for the entire groups of workstations, can be performed from the one location and at a given time;

- Expanding the possibilities of the Active Directory - Some applications have the possibility to be implemented directly into the Active Directory, so their management and administration becomes a part of the Active Directory.

The Image Services are, so far, shown up to be the best and the most economical solution for the publishing of the aerophoto images, which serves as a base map for the further processing. For that purpose, the extension Image for the ArcGIS Server is installed, and it is used for publishing of the image services, as the addition for desktop version of the used software, or as a WEB service. This server component addition, enables the creation of the dynamic mosaics, and, in the real time, processing of a large number of the aerial images. Publishing of the aerial images over the image service, gives the extra quality to the aerial images, it simplifies their management, maintenance and provides faster and easier access for the users.
The advantages of the implementation of image services are: simplified management of the aerial images; enables publishing of the large amount of the aerial images without the need for them to be pre-processed; possibility to create mosaics of the aerial images in different file formats, projections, locations and resolutions; processing of the data is performed in the real time on the server, which frees the resources of the client workstation; publishing of the special services at the meta data level; defined area of the interest can be sliced out from the image service and then used on the workstation while offline.

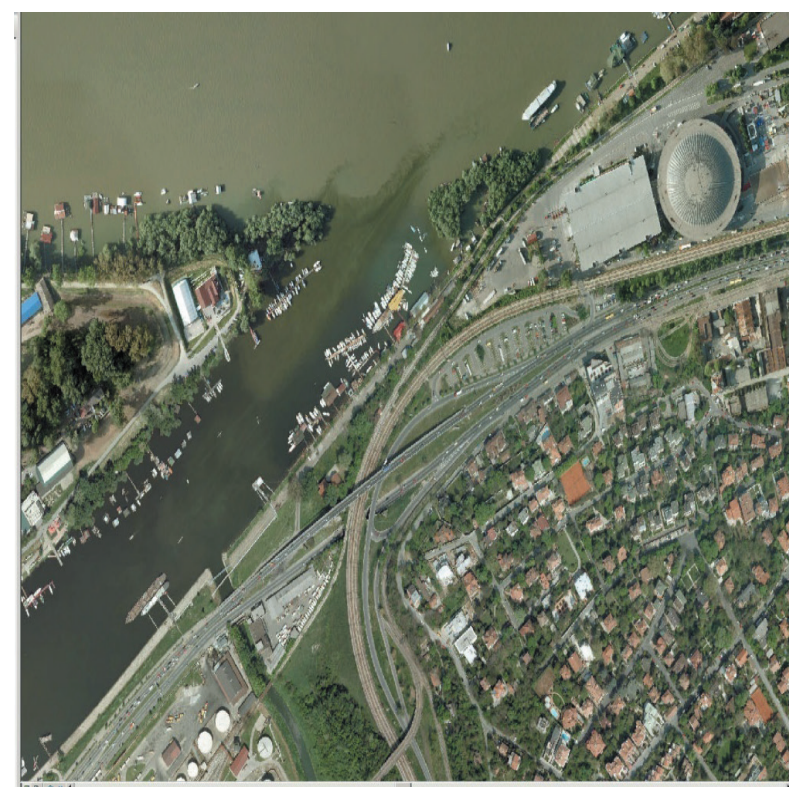

Fig. 1. Published image service in IS MGI

(Pavlović A., 2014)

\section{SPATIAL DATAAND TECHNOLOGICAL PROCESS OF TOPOGRAPHIC MAP CREATION}

Usage of the IT technologies, makes the production process of topographic maps a lot easier and faster. The contemporary trends in the sphere of the data acquisition, organization and manipulation of the spatial data, imposes the existence of the central geodatabase. In practice, it means the unification of all geospatial data into a single database, from which, a variety of topographic and overview map scales can be created or derived. The significance and usefulness of the production process based on the central database can also be observed through the improved data availability, possibility of the multiscalar presentation, easier administration, elimination of the data and the process redundancy and standardization. All of the above mentioned advantages, reduces the time necessary for creation of maps, as well as lowering the total cost of final product - the map. 
The creation and definition of the central database [1], and the entire production process of topographic maps based on the central database, is a demanding and complex task. It requires multidisciplinary approach. In the favor of this statement, there is a fact that many developed countries did not yet completely develop their own solutions for this problem. It is necessary to create the central database in a way that supports the definition of the production process, which will resolve the problem of multiscalar view of the spatial data and enables support for all phases in the production process of the map creation.

MGI has created the central database and defined the production process in the 2012. The central database is used as a base for the creation of the entire scale array of the digital topographic maps, which are supposed to be produced in MGI. Those map scales are 1:25000, 1:50000, 1:100000 (topographic maps) and 1:250000 (overview topographic map). [2]. While defining the production process based on the central database (Fig. 2.), it was planned that the initial data acquisition will be conducted using contemporary methods of photogrammetric restitution, direct mapping over digital ortophoto and cartographic processing of the content collected that way in the GIS environment, with the usage of the corresponding alphanumerical data and the data collected and verified on the field.

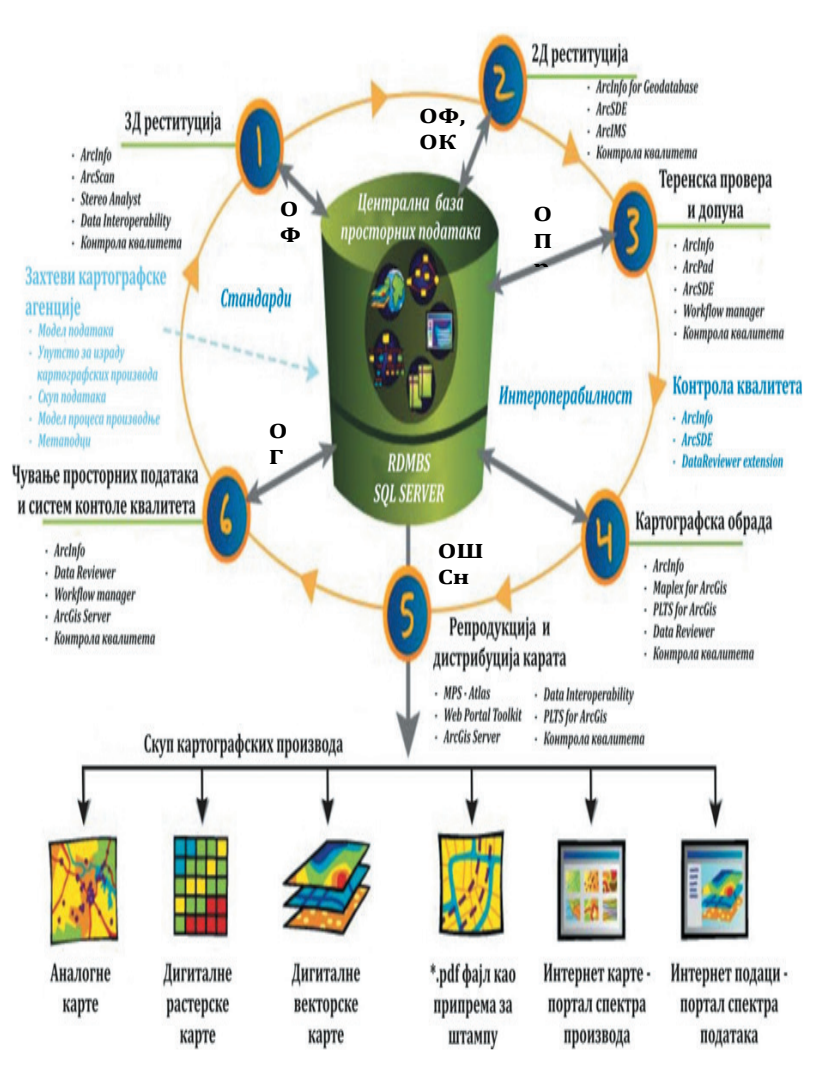

Fig. 2. The production process of topographic maps in the MGI (MGI, 2015)
The entire process of map production in MGI, was conducted with the consideration of the end user needs. Those users are mainly Serbian Armed Forces, different business entities as well as interested civilians. The specific requirements of the different users are involved into the central database, from which, we can get visualized (mapped) data, according to the user request. From the given schema of the production process of the topographic maps in the central database environment, can be noticed that, in the production process, all departments are included and supported [2]. Those departments, in the production sector, are namely: Photogrammetric department (OF), Survey department (OPr), Cartography department (OK), and in the support sector: Geoinformatic department (OG), Publishing and suppliement department (OŠSn). Functions and responsibilities are narrowly and clearly defined by the order and connection of the every phase in the production process.

The main source of the data acquisition in the central database are data obtained by the digital technological process for aero photogrammetric imaging in the MGI [3]. Digital technological line in the MGI consists of the airplane Piper Seneca, digital aero photogrammetric camera Leica ADS80, with additional equipment, and photogrammetric workstations with the software for the $3 \mathrm{D}$ restitution. Digital technological line for aero photogrammetry in the MGI is shown in figure 3. The data obtained with the method of the aero photogrammetry imaging (digital aero photogrammetric camera), are processed on the photogrammetric workstations with the usage of the specialized 3D software, directly in the central geodatabase. With the procedure of the ortorectification, aero photogrammetric images, with the usage of the collected 3D spatial data and the orientation points, are transformed from central to the orthogonal projection, and the final result is a digital ortophoto.

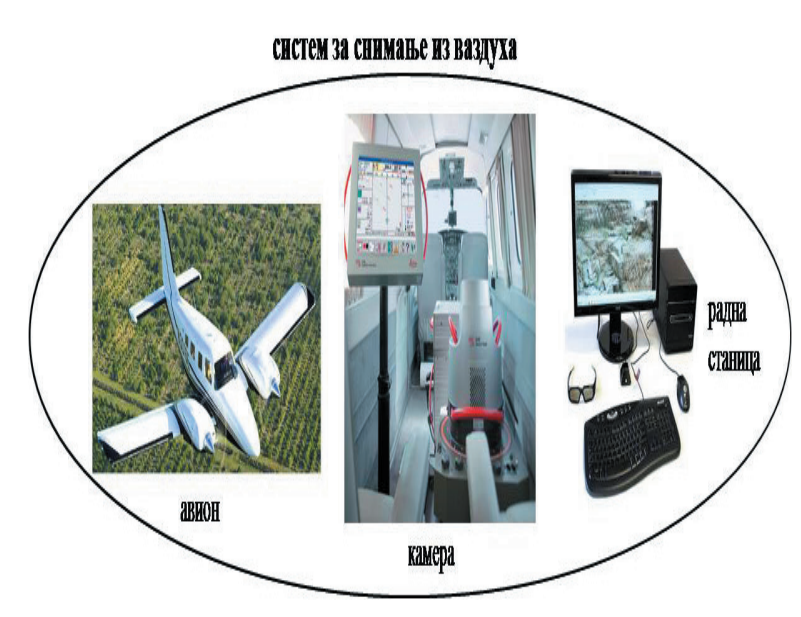

Fig. 3. Technological line for aerophoto imaging (MGI) 
The phases of the technological process are all conducted in the central database environment. The different phases in the production process require additional software, but, almost the entire production process is based on the ESRI's ArcGIS platform [4].

After the creation of the digital ortophoto, first phase of the production process is the $3 \mathrm{D}$ restitution. The $3 \mathrm{D}$ restitution is conducted with the usage of the Stereo Analyst extension for ArcGIS. Usage of this extension allows us to perform 3D editing in the central database environment, without the need for usage of the third party software. It also allows us to use internally standardized data model and simplifies the entire production process. The $3 \mathrm{D}$ restitution is followed by $2 \mathrm{D}$ restitution. The $2 \mathrm{D}$ restitution introduces the cartographic modeling of the content obtained by $3 \mathrm{D}$ restitution method and the additional content which was not treated in the $3 \mathrm{D}$ restitution process. This phase of the production process of the creation of the maps is completely conducted in the ArcGIS software environment (the editor version), by direct vectorisation over the digital ortophoto in the SQL database, which is a part of the entire workflow as a distributed database. The map content that passed the phases of 3D and 2D restitution has to be field checked, so the next phase of the production process is a field check and the addition of the data. For this phase we use the ArcPAD software and the tablet devices. This approach allows us to stay within defined environment of the central database even while disconnected from the MGI LAN [5]. That means that field checked and updated data, are automatically integrated in the central database.

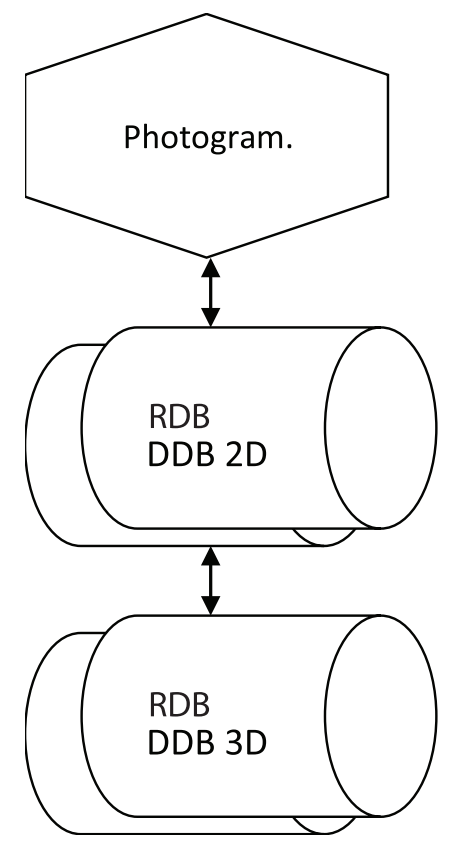

Fig. 4. Part of the production proces based on the distributed databases
That means that field checked and updated data, are automatically integrated in the central database. The final phase of the production process which includes data manipulation, is the cartographic processing of the previously collected and partly processed data. For the cartographic processing we use, like in the $2 \mathrm{D}$ restitution, ArcGIS software, and it is based on the interactive processing of the generated content, with the usage of the cartographic modeling methods [5]. In this phase of the production process, the map is completely generated in the means of the visualized content and supported SQL database as well. This is the last phase of the production process for the GIS content. The last phase of the production process that considers the creation of the hard copy map, is printing. Printing process is partially based on the central database, from which the data is visualized and exported in the PDF file format, and partially on the third party software such as Adobe Illustrator and Map Publisher. This is necessary because the final result, or hard copy map, has to be printed on the analog offset printing machine.

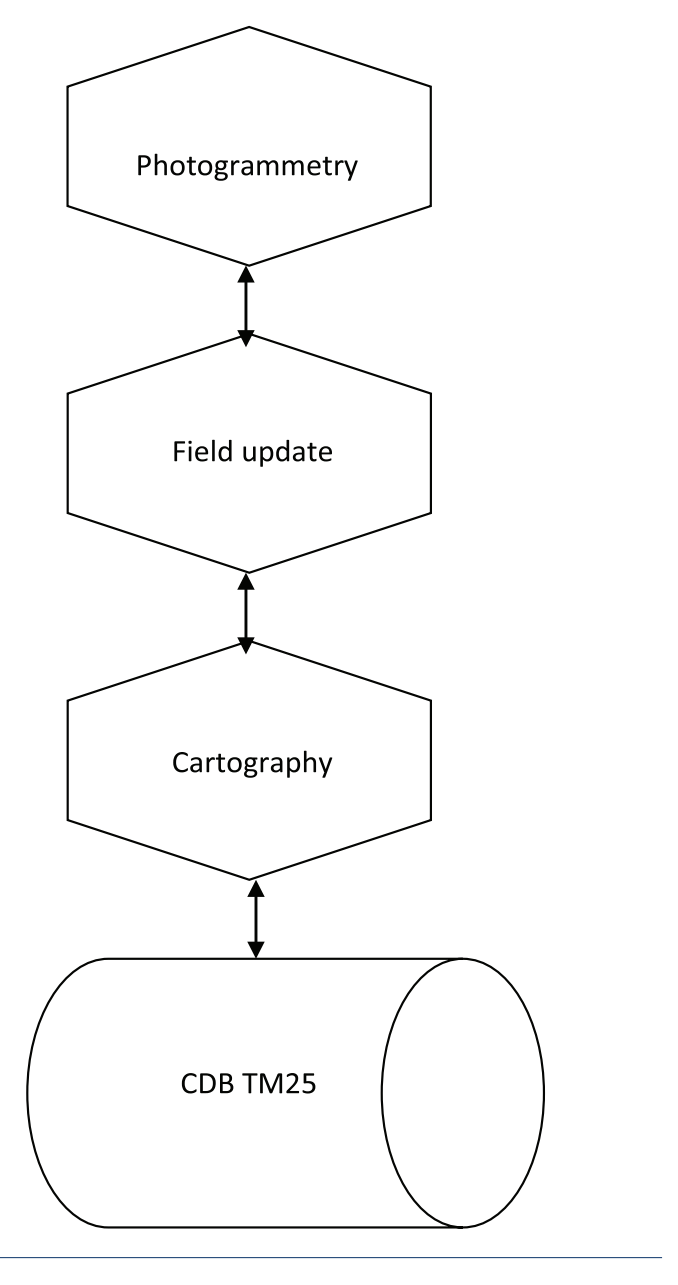

Fig. 5. The Schematic representation of the production process at the central database level 


\section{CONCLUSION}

The MGI of the Serbian Armed Forces is bond to it's tradition of the map creation, topographic maps espetially, since 1876. In comparison to the previous epochs, nowadays IT and the influence of the informatics revolution has the significant impact on the way that topographic maps are created. That led to the evolution of the production process of topographic maps in the MGI as well. According to the implementation of the IT, the entire production process of the topographic maps in the MGI is implemented. In the very beginning, the expenses were much higher then with usage of classic approach of the topographic maps production, due to the high investment into hardware and software. As the time passes, the expenses are lowering and in a certain moment, they become lower then classic cartographic map production approach. The improved quality of nowadays topographic maps produced in the MGI, is a large advantage of the IT based production process in comparison to the traditional production process [6]. That is achieved by the centralization of the production process, unification of the symbology and quality control and many other technical solutions based on the IT. By these unified and centralized steps of the production process, the possibilities of the arbitrariness and inconsistency are almost eliminated.

Using the contemporary technological solutions in the sphere of the map production, as a main product, now we have a geospatial database. Different kinds of the hard copy maps and digital maps are only the types of the layout of the geospatial database.
Beside these traditional layouts (maps), geospatial database also enables publishing of the map content on the WEB, and as our main goal for the future, updates of the map content in the real time, over the WEB.

The map production process, which is shown in this paper, is not unchangeable and final. It is intentionally left open for the future expansions of the capabilities, according to the advances in the IT. Because of that, it is necessary to keep track on the newest IT achievements, even when they are not primarily intended for mapping purposes.

\section{REFERENCES}

[1] Vojnogeografski institut, "Tehnička dokumentacija VGI," Beograd, 2014.

[2] V. Marković, A. Pavlović, D. Radosavljević, "Proizvodni proces DTK25 u VGI, ”Beograd, 2017.

[3] S. Tatomirović, R. Banković, V. Marković, "Tehnološki proces izrade digitalne topografske karte 1:25000," Conf. Oteh 2009 Beograd, pp. 748-751, 2009.

[4] http://www.esri.com

[5] V. Marković, "Opšti principi logičkog modelovanja strulture podataka za potrebe izrade DTK25," in Zbornik radova VGI, Beograd, pp. 23-31, 2009.

[6] S. Tatomirović, R. Banković, Lj Nikoloski, S. Milošević, "Quality control of digital topographical map 1:25.000," Conf. Oteh 2011 Beograd, pp. 711719, 2011. 